\title{
INTERNATIONAL PERSPECTIVES \\ The Lay of the Land: An Overview of Canada's Undergraduate Research Opportunities within the Life Sciences
}

Evelyn Sun, Marcia L. Graves, David C. Oliver, University of British Columbia

\begin{abstract}
This article reviews the state of Canada's undergraduate research opportunities (UROs) in the life sciences across various institutions. Survey data gathered in 2019 from 20 departments in 14 universities show that all responding departments offer well-established forms of research that include credit-based directed studies or honors-thesis courses. Paid research opportunities are offered by $80-95$ percent of the responding departments. Newer-generation UROs such as course-based undergraduate research experiences and inquiry-based lab courses were found to be offered by more than half of responding departments. Additionally, 60 percent reported having co-curricular and student-driven URO initiatives. Overall, the survey data reflect a well-established and growing portfolio of UROs at universities across Canada.
\end{abstract}

Keywords: Canada, co-curricular, co-op, course-based undergraduate research experiences, undergraduate research experiences, undergraduate research opportunities

\section{doi: $10.18833 /$ spur/4/1/16}

Undergraduate research experiences (UREs) provide wideranging benefits for students, which positively impacts the scientific community at large (Russell et al. 2007; Sadler et al. 2010). Students who participate in hands-on research gain an array of technical and transferable skills while deepening their disciplinary knowledge. They build skills in oral and written communication, project coordination, interpersonal skills and teamwork, critical analysis and problem solving, organization and time management, technical skills, data collection, and a higher regard for ethical considerations (Bauer and Bennett 2003; Sadler et al. 2010). Undergraduate researchers practice "doing science" and scientific thinking, which leads them to develop a more nuanced appreciation of the nature of science, and the limitations and complexity involved in collecting and evaluating scientific evidence (Sadler et al. 2010). Furthermore, UREs promote scientific enculturation, a stronger sense of belonging and scientific identity (Estrada et al. 2018; Adedokun et al. 2013; Berkes 2007), which is suggested to be a critically important factor that influences if students pursue a career in science.

Given that the outcomes gained by students participating in UREs influence their career choices, it is not surprising that UREs directly impact the future of the scientific community. It has been reported that UREs increase student awareness, interest, and confidence in pursuing careers in STEM (science, technology, engineering, and math) (Russell et al. 2007; Sadler et al. 2010). This leads to higher retention or persistence in the STEM fields, as students who participate in UREs are more likely to pursue an advanced degree after graduation (Hathaway et al. 2002; Eagan et al. 2013; Zydney et al. 2002). Importantly, correlation between UREs and persistence in science as a career has been observed in underrepresented groups, which speaks to the influence of UREs in diversifying the scientific workforce (Estrada et al. 2018; Hernandez et al. 2018). Taken together, UREs are a high-impact educational opportunity that offer enormous benefits to students and the research community. It is therefore important to characterize opportunities for UREs across undergraduate curricula to maximize and broaden access to these benefits.

UREs are a product of various types of undergraduate research opportunities (UROs) that include (1) traditional lab courses involving instructor guided experiments; (2) paid or unpaid internships, which in Canadian institutions are often called co-op work experience and directed studies/honors thesis courses, respectively; (3) inquiry-based 
lab courses involving investigation without novelty; (4) high-enrollment, course-based undergraduate experiences or CUREs involving novel, self-directed investigations; and (5) other co-curricular UROs involving programs and/ or learning activities that align with a student's academic goals that involve research. In this article, URO is the term used to describe the various types of undergraduate research, whereas URE is used to describe the outcome of an URO (e.g., research-related activities that students engage in as part of a URO). For example, although both traditional lab courses and co-op are UROs, they do not offer the same type of URE due to the differences in mentorship, environment, and other factors.

Historically, UROs offered by universities have included mentor-mentee models (e.g. unpaid, credit-based, directed studies courses; unpaid or paid internships or volunteerships; paid co-op work experience) in which an undergraduate student conducts research in a grant-funded academic laboratory, government laboratory, or a company under the direct supervision of a more advanced researcher (e.g., a graduate student, postdoctoral fellow, principal investigator, or staff scientist). Although the quality of the research mentorship experience can vary, the long-standing mentor-mentee model has generally been successful. However, the one-to-one nature of this model means that it lacks scalability and can limit diversity and equitability due to the self-selecting process of student recruitment. More recently, CUREs have been developed as a scalable and accessible solution to the need and student-led demand for more UROs. The development of CUREs, as well as student-led team-based research options like International Genetically Engineered Machines (iGEM) and BioMod, represent a newer generation of UROs that are garnering notable interest from both students and educators.
In this article, the authors describe the current structure, function, and diversity of life sciences UROs within Canada. Universities were targeted that have departments focused on the life sciences (defined by titles including biology, microbiology, immunology, biochemistry, botany, and zoology) to allow meaningful institutional and departmental alignments. It was reasoned that UROs in more distantly related departments/disciplines (e.g., physics versus biology) may be quite different with respect to their scientific histories, technical requirements, and/ or administrative structures, thus making comparisons difficult. In contrast, UROs within the life sciences (e.g., biochemistry versus microbiology) would share more similar underpinnings.

It is hoped that this review provides a useful snapshot of UROs offered within life sciences in Canada as of 2020. This new insight may be leveraged to compare and contrast different UROs, and their resulting UREs, within and between Canadian institutions. It may also provide a basis for comparison with models of undergraduate research established and evolving in other countries.

\section{Canada's Undergraduate Research Opportunities within the Life Sciences}

Canada is a country with a population of approximately 38 million individuals. The country spans a total area of approximately 10 million $\mathrm{km}^{2}$, divided into 10 provinces and 3 territories. Canada was reported to have 96 universities in total as of 2016. Most universities are located along Canada's southern border due to its temperate climate relative to the northern regions of the country (see Figure 1).

The majority of Canada's postsecondary institutions are publicly funded by the federal and provincial govern-

\section{FIGURE 1. Canadian Postsecondary Institutions Represented in Survey Data}

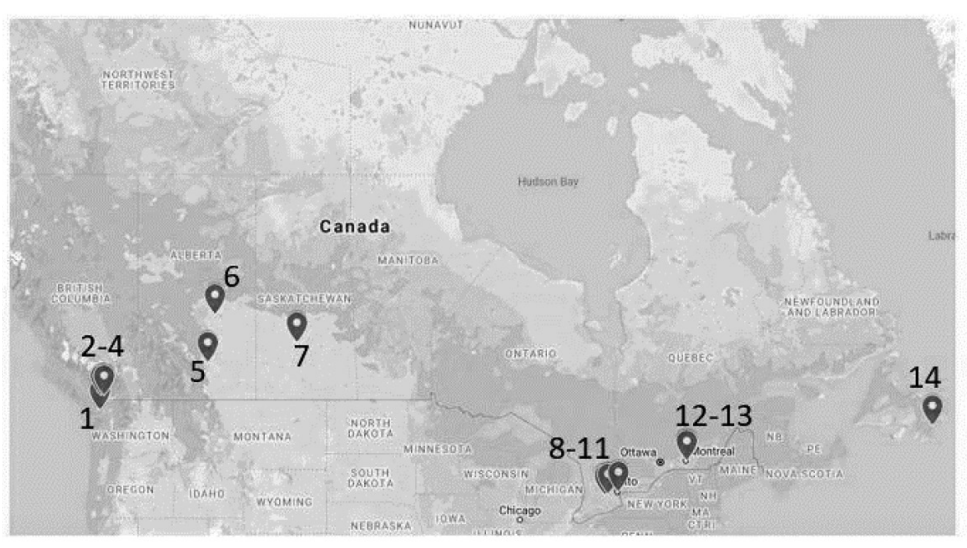

1. University of Victoria

2. University of British Columbia

3. Simon Fraser University

4. British Columbia Institute of Technology

5. University of Calgary

6. University of Alberta

7. University of Saskatchewan

8. University of Waterloo

9. Wilfrid Laurier University

10. University of Guelph

11. University of Toronto

12. Concordia University

13. McGill University

14. Memorial University of Newfoundland 
ments. Universities tend to directly support pedagogical development and/or course renewal efforts; national or provincial funding programs for teaching and learning do not exist. Funding for undergraduate research opportunities is generally channeled through faculties or schools (e.g., science) overseeing disciplinary departments (e.g., microbiology or zoology); however, specific institutional programs such as the Projects for Undergraduate Research Experiences at the University of British Columbia (UBC) have been implemented at the institutional level to support innovation.

In Canada, grant-driven research laboratories operate under the funding structure provided primarily through two major government funding agencies: Natural Sciences and Engineering Research Council (NSERC) and Canadian Institutes of Health Research (CIHR). NSERC offers two streams of undergraduate research funding that includes the Ingenium-NSERC Steam Horizon Award, which broadly encompass various areas of STEM involvement including research; whereas the Undergraduate Student Research Awards (USRA) specifically funds UREs across various research areas or disciplines (NSERC, Government of Canada 2016). USRA is provided as a one-term (16-week) stipend to partially support student research in a grant funded academic lab. The remaining balance of the stipend is provided by the principal investigator or institution. In partnership with various sponsors, CIHR also offers a variety of funding opportunities with an emphasis on life sciences research including the Undergraduate Summer Studentship Award. These scholarships support students pursuing general research over the summer term (typically May to August) as well as other more specialized, niche opportunities such as the mobility, musculoskeletal health and arthritis fund, which is used to support undergraduate research specific to one area (CIHR, Government of Canada 2019).

Canadian undergraduate degree programs in the life sciences typically involve 4 to 5 years of coursework. Students select a degree program and/or specialization after year 1 or year 2. Most degree programs, as well as traditional UROs, are coordinated at the departmental level. Some universities offer integrated degree programs that allow students to combine disciplines (e.g., microbiology and physiology). However, because these programs can lack direct department affiliation student access to UROs may be restricted. To address this issue, the integrated sciences program at McMaster University affords all the enrollment privileges of an undergraduate student in a program entirely hosted in that concentration's home department.

In Canada, universities coordinate a range of life sciences UROs, which include (1) the long-standing mentor-mentee models such as directed studies or honors thesis courses, summer undergraduate research experiences (SUREs), volunteering, and instructor-led teaching laboratory experiences; (2) co-op work experience; (3) course-based undergraduate research experiences; and (4) co-curricular, student-driven programs. To gain insight into the scope and diversity of UROs in the life sciences across Canada, a survey of faculty and administrators was conducted in 2019. The survey was sent out to life sciences departments of universities that were listed in the Maclean's magazine rankings of the top Canadian medical and comprehensive universities; a total of 40 departments at 25 institutions was contacted. Life sciences departments included biochemistry, biology, biotechnology, microbiology, and immunology. The response rate was approximately 50 percent, which represents 20 departments across 14 institutions as summarized in Table 1. A biological sciences department was represented from all 14 institutions. Biochemistry departments were represented by the University of Victoria (UVic), UBC, and McGill University. The Department of Microbiology (and Immunology) was represented in Memorial University of Newfoundland, UVic, McGill, and UBC. The responding biotechnology program is co-hosted by the British Columbia Institute for Technology and UBC.

All the responding departments (20 out of 20) indicated that they offer mentor-mentee directed studies and/or honors thesis courses, opportunities for volunteer work experience, and instructor-led teaching laboratory courses. These experiences collectively represent the long-standing models of UROs in Canada. Credit-based courses are funded through departmental budgets derived from institutional funding. Reagents and supplies required for directed studies, honors thesis projects, or volunteer lab assistant work are purchased by research grants held by the host laboratory.

Co-op work experience programs or paid internships are well established throughout Canadian institutions with more than 80 percent (16 out of 20) respondents confirming a functional program at their university. Co-op work experience is typically limited to students in the second to fifth year of their undergraduate degree. Programs are generally operated by coordinators who staff a central office. Prospective employers post job advertisements via the co-op office website to which students apply and interview. Positions are typically 4- or 8-month terms, although 12- or 16-month terms are possible. Students work in companies, government labs, or academic research labs locally, in other areas of Canada, or internationally. Funding for co-op work experience can be provided by industrial firms, government employers, as well as grant-funded academic research labs. NSERC USRA funding can be used to supplement a co-op work experience stipend.

Another type of paid internship is the summer undergraduate research experience (SURE), most commonly held from May through August, although winter placements 
TABLE 1. Canadian Institutions Represented in Survey Data

\begin{tabular}{|c|c|c|c|}
\hline & Province & $\begin{array}{l}\text { Total undergraduate } \\
\text { students enrolled }\end{array}$ & Represented departments in survey \\
\hline British Columbia Institute of Technology (BCIT) & $\mathrm{BC}$ & $18,147^{\mathrm{a}}$ & Biotechnology (UBC-BCIT joint program) \\
\hline Concordia University & QC & $37,154^{\mathrm{b}}$ & Biology \\
\hline McGill University & $\mathrm{QC}$ & $27,035^{\mathrm{c}}$ & $\begin{array}{l}\text { Biology } \\
\text { Biochemistry } \\
\text { Microbiology and Immunology }\end{array}$ \\
\hline Memorial University of Newfoundland & $\mathrm{NF}$ & $13,564^{\mathrm{d}}$ & Biochemistry \\
\hline Simon Fraser University & $\mathrm{BC}$ & $29,904^{b}$ & $\begin{array}{l}\text { Biological Sciences } \\
\text { Molecular Biology and Biochemistry }\end{array}$ \\
\hline University of Alberta & $\mathrm{AB}$ & $28,709^{\mathrm{e}}$ & Biological Sciences \\
\hline University of British Columbia (UBC) & $\mathrm{BC}$ & $44,882^{\mathrm{b}, \mathrm{f}}$ & $\begin{array}{l}\text { Biology (Botany and Zoology) } \\
\text { Biochemistry } \\
\text { Microbiology and Immunology }\end{array}$ \\
\hline University of Calgary & $\mathrm{AB}$ & $23,808^{\mathrm{b}}$ & Biological Sciences \\
\hline University of Guelph & $\mathrm{ON}$ & $26,677^{\mathrm{d}}$ & Molecular and Cellular Biology \\
\hline University of Saskatchewan & SK & $18,103^{\mathrm{g}}$ & Biology \\
\hline University of Toronto & ON & $71,930^{\mathrm{b}}$ & Biochemistry \\
\hline University of Victoria & $\mathrm{BC}$ & $18,714^{\mathrm{c}}$ & $\begin{array}{l}\text { Biology } \\
\text { Biochemistry and Microbiology }\end{array}$ \\
\hline University of Waterloo & ON & $33,322^{c}$ & Biology \\
\hline Wilfrid Laurier University & ON & $15,622^{\mathrm{e}}$ & Biology \\
\hline
\end{tabular}

Note: Enrollment numbers were collected from each institution's main website. Departments that were surveyed included biochemistry, biology, biotechnology, and microbiology to reflect life sciences disciplines. Information in the table was collected from British Columbia Institute of Technology n.d.; Concordia University n.d.a; Enrolment Services, McGill n.d.; Institutional Analysis \& Planning, University of Waterloo 2015; Memorial University of Newfoundland n.d.; Simon Fraser University n.d.; University of Alberta n.d.a; University of British Columbia n.d.a; University of Calgary n.d.a; University of Guelph n.d.

${ }^{\mathrm{a}}$ Full-time as of $2017-2018$

${ }^{\mathrm{b}}$ As of 2018-2019

${ }^{\mathrm{c} A s}$ of fall 2019

${ }^{\mathrm{d}}$ As of 2017

'Full time as of 2018-2019

${ }^{\mathrm{f}}$ Vancouver campus only

${ }^{\mathrm{g}}$ As of $2019-2020$

sometimes occur. During SUREs, students typically conduct 16 weeks of full-time research in a grant-funded research lab. Federal funding supports the NSERC USRA program, and awards are allocated to each institution, which then distributes individual allotments of awards to faculties and departments. Award allocation schemes at the departmental level are customized. SURE awards are commonly funded by the host institution as well, thereby increasing the universities' annual quota of paid UROs. Since NSERC USRA awards are only available to students with Canadian citizenship or permanent resident status, some institutions offer a subset of awards specifically for students with international status. For example, UBC operates a Work-Learn International Undergraduate Research
Awards program, which provides equivalent funding to a USRA. It is also noteworthy that USRA places an emphasis on supporting self-identified Indigenous students, as the program recommends that institutions can submit applications from all Indigenous students even if the institution's academic award quota has been reached.

Newer generation models of credit-based courses include inquiry-based teaching labs and the so-called course-based undergraduate research experiences (CUREs). Inquirybased lab courses are offered by 14 of 20 (70 percent) of the responding departments, whereas CUREs are offered by 13 out of 20 of the responding departments ( 65 percent; see Figure 2). CUREs are relatively new pedagogi-

66 Scholarship and Practice of Undergraduate Research 
FIGURE 2. Undergraduate Research Opportunities Provided in 14 Canadian Postsecondary Institutions

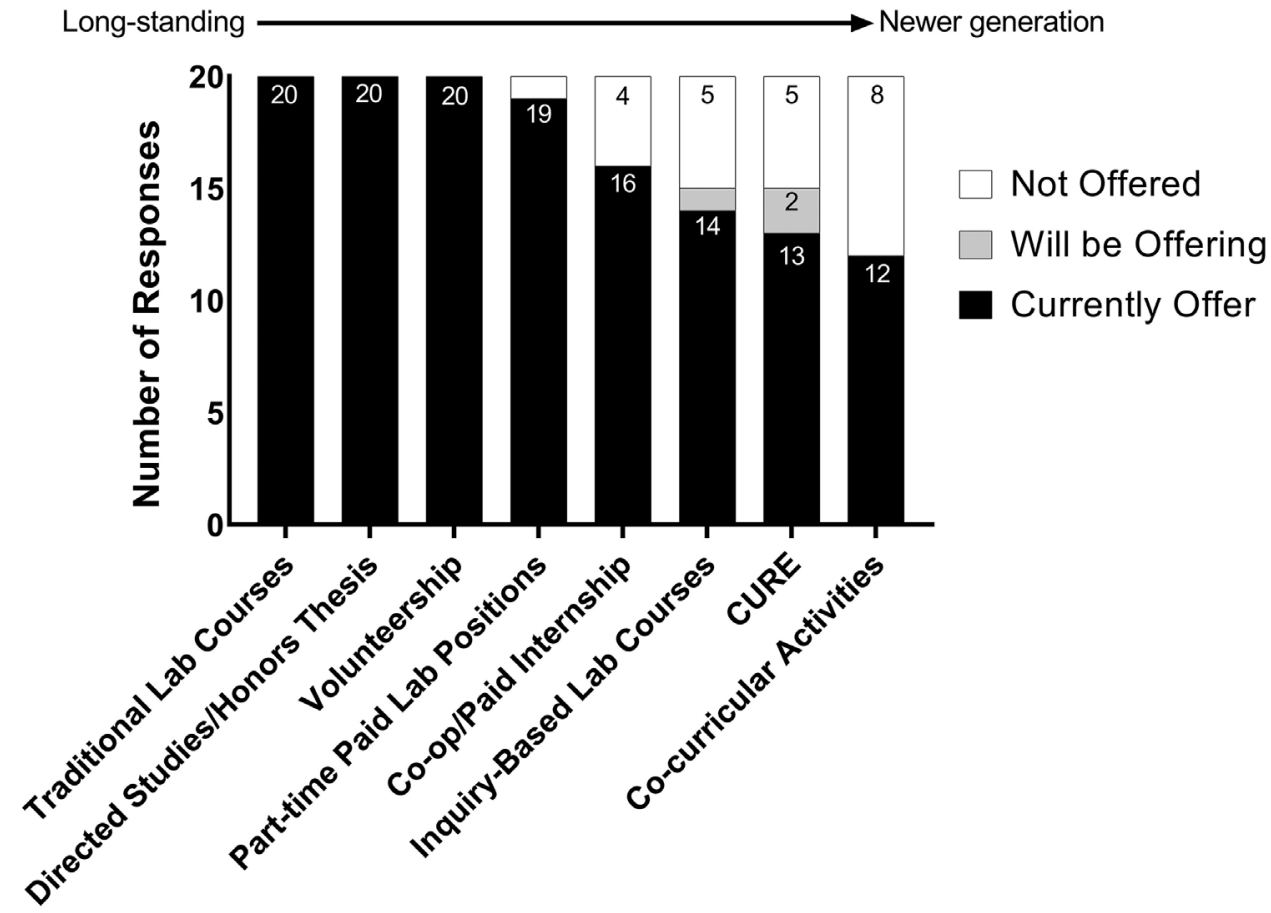

Note: Summer undergraduate research experiences (SUREs) are a part of the co-op/paid internship category.

cal innovations in which students typically work in teams on authentic research projects (i.e., the outcome of the research is unknown to the students and instructor at the outset). An instructor or instructors facilitate CUREs, guiding a class of students (e.g., a few to hundreds) divided into teams that work on often different research questions (in comparison to the one-to-one mentor-mentee model followed by honors theses and directed studies courses). The CURE model has the distinct advantage of being scalable and accessible to a broad range of undergraduate students. McGill's Department of Microbiology and Immunology operates CUREs through open-source, community-based programs such as SEA-PHAGES (Science Education Alliance, HMMI n.d.) and Tiny Earth (n.d.). These two initiatives act as consortia of student-sourced antibiotics and viruses discovered in soil respectively. Since 2001, the UBC Department of Microbiology and Immunology has offered molecular microbiology CUREs in which teams of fourth-year students undertake novel, self-directed research projects in the span of one term. Findings are published in an undergraduate research journal and prime the design of subsequent research questions in a feed-forward manner. The University of Saskatchewan (USask) has recently adopted the CURE model developed in the UBC Department of Microbiology and Immunology to create the new course Team-Based Experimental Microbiology.

CUREs have been positively perceived not just by students but also by faculty as a means of effectively integrating research into a teaching environment to help students develop core research competencies (Shortlidge et al. 2016; Auchincloss et al. 2014). The development and implementation of CUREs requires institutional and faculty commitment. Barriers to CURE implementation include instructor time, available funding, logistics of operation, and faculty buy-in (Spell et al. 2014; Shortlidge et al. 2016). However, it is heartening to report that the majority of responding life science departments in Canada offer CUREs, reflecting a healthy commitment to pedagogical innovation. Although a comprehensive review of CUREs in Canada is beyond the scope of this article, it will be interesting to see how this model develops in Canada over the next few years.

Exciting new co-curricular, student-driven life sciences URO initiatives are afoot in Canada. Team-based programs such iGEM and BioMod have been established at several Canadian universities (see Table 2). The international competiton iGEM challenges student teams to design, develop, test, and disseminate innovative synthetic biology solutions to real-life problems. Teams receive varying levels of guidance and mentorship from graduate students, faculty, and industry partners. Funding is sourced by students from their home institutions as well as industrial sponsors. Canadian iGEM projects include the development of novel DNA constructs (University of Ottawa 2019), plastic degradation (University of Toronto n.d.b), approaches to improvements in canola oil production (University of Calgary n.d.b), and a neurotoxin biosensor for safer shellfish consumption (University of British Columbia n.d.b). BioMod is a smaller but rapidly growing initiative that is 
TABLE 2. Examples of Molecular Biology Co-Curricular Programs Hosted by Canadian Institutions

\begin{tabular}{|c|c|}
\hline $\begin{array}{l}\text { Co-curricular program } \\
\text { and focus }\end{array}$ & Institution and reference \\
\hline \multirow{10}{*}{$\begin{array}{l}\text { iGEM: Competition-based } \\
\text { program that involves teams } \\
\text { of students working to solve a } \\
\text { community-based problem in } \\
\text { the field of synthetic biology }\end{array}$} & Concordia University (n.d.b) \\
\hline & Dalhousie University (n.d.) \\
\hline & McGill University (2018) \\
\hline & University of Alberta (n.d.b) \\
\hline & $\begin{array}{l}\text { University of British Columbia } \\
\text { (n.d.b) }\end{array}$ \\
\hline & University of Calgary (n.d.b) \\
\hline & University of Guelph (2019) \\
\hline & University of Ottawa (2019) \\
\hline & University of Toronto (n.d.b) \\
\hline & University of Waterloo (n.d.) \\
\hline \multirow{2}{*}{$\begin{array}{l}\text { BioMod: A biomolecular } \\
\text { design competition for } \\
\text { undergraduate students } \\
\text { intended to develop problem- } \\
\text { solving skills and teamwork }\end{array}$} & $\begin{array}{l}\text { University of British Columbia } \\
\text { (n.d.c) }\end{array}$ \\
\hline & University of Toronto (n.d.c) \\
\hline
\end{tabular}

attracting students interested in biomolecular design. At Concordia University, the Biology Student Association has been organizing trips to the Galapagos Islands since 2006 to conduct conservation-based projects that count for course credit.

Several institutions across Canada have internal initiatives or organizations that help connect students to UROs. The Undergraduate Research Initiative at the University of Alberta ( $U$ of A) operates as an institutional office that provides consultation, hosts networking events, and provides online resources to help students UROs. Other budding prospects are student-led organizations that promote undergraduate research opportunities. At Simon Fraser University, the SFU Science Undergraduate Society provides students with three potential avenues of research dissemination and networking: publication in the $S F U$ Science Undergraduate Research Journal (SURJ n.d.), an annual poster competition, and/or exposure of UREs through a curated blog (SURJ n.d.). At UBC, a multidisciplinary team of students have come together to form the club Undergraduate Research Opportunities, which hosts programs and events such as Life Science Research Night, where students learn about careers in research and interact with academics and industry professionals, and the Research Exchange Program (REX), in which students conduct paper-based research projects under the guidance of academic mentors. The students leading the Undergraduate Research Opportunities Club at UBC collaborate with faculty advisers, as well as university staff, in the Centre for Student Involvement and Careers (CSI\&C) who provide mentorship and administrative support to the students. This tripartite relationship among the club, faculty, and CSI\&C creates a model of student-centered leadership to centrally organize and share information about access to UROs.

Mechanisms for the dissemination and celebration of undergraduate research such as an undergraduate research symposia and undergraduate research journals exist at several Canadian institutions. USask publishes the multidisciplinary University of Saskatchewan Undergraduate Research Journal (USURJ) each year (University of Saskatchewan n.d.a). As mentioned previously, Simon Fraser University publishes the SFU Science Undergraduate Research Journal (SURJ) operated by its Science Undergraduate Society (SURJ n.d.). UBC is home to the Undergraduate Journal of Experimental Microbiology and Immunology (UJEMI n.d.). Initiated in 2001 as a means to disseminate the results of student projects in CURE courses in microbiology and immunology, UJEMI now has a peer-review arm that invites submissions from undergraduate students around the world (Sun et al. 2020)

Undergraduate research symposia were reported by multiple institutions as platforms for communicating the outcomes of UROs. UBC hosts the Multidisciplinary Undergraduate Research Conference (MURC) with oral and poster presentations with hundreds of participants per year (Student Services, UBC 2016). Similarly, the University of Ottawa offers an Annual Undergraduate Research Opportunity Program Symposium to allow students across various disciplines to present their research in the format of a poster, hosting more than 260 presenters a year (University of Ottawa 2020). The UBC Department of Microbiology and Immunology hosts an undergraduate research symposium each year (MBIM URS) that provides a forum for students to disseminate their research, network with their peers and other academics, and demonstrate formal participation within the scientific community. More broadly, the annual Undergraduate Research in Science Conference of Alberta is an initiative hosted by various different Canadian institutions in Alberta that allows students who are conducting NSERC-funded projects to present their work. Ontario hosts a similar province-based event, Ontario Biology Day, where biology students can present their research and network. The Prairie University Biology Symposium is an annual event, founded at the University of Manitoba, that hosts presentations from undergraduate students to postdoctoral fellows across Western Canadian institutions.

The popular three-minute thesis (3MT) competition, which is typically reserved for the presentation of graduate student

68 Scholarship and Practice of Undergraduate Research 
theses, has recently been reimagined at $\mathrm{UBC}$, which rolled out its first 3MT competition for undergraduate students in 2020. Spearheaded by UBC's Biochemistry Department, the $3 \mathrm{MT}$ competition provides a forum for undergraduate students in directed studies courses, honors courses, and capstone research-based courses (e.g., CUREs) to present their research projects. To level the field, emphasis is placed on communicating project background and scientific concepts as opposed to experimental data.

Finally, student participation in a URO can be recognized as course-credit, documented in their transcript, or associated with certification. For example, participation in two or more internship terms is recognized at McGill on student transcripts and conversion to a co-op degree, specifically for the joint computer science and biology program. UBC offers certification for completion of the co-op program. The $U$ of A also offers an undergraduate research certification to recognize URE participation. The USask Department of Biology more recently adopted a certificate on biology research to recognize students who participated in a minimum number of intensive research-based courses.

\section{The Future of Undergraduate Research in Canada}

The survey data show that long-standing URO models (e.g., directed studies courses, co-op, or volunteering) are offered and well supported by all the responding institutions and that newer URO models (e.g., CUREs; co-curricular student-led initiatives) that are scalable and more broadly accessible have been well established in many institutions or are emerging. As demand for UROs increases, there is a growing need for a cohesive model for supporting their development and maintenance. Canada's model for supporting UROs is linked to funding from the federal government, internal funding from public universities, and industry sponsors. It is exciting to report strong support overall for pedagogical innovation and funding for undergraduate research in Canada within the life sciences. Given the well-established benefits of UREs, providing equitable access to UROs (paid and unpaid) to as many students as possible is a challenge that Canadian postsecondary institutions are seeking to address.

\section{References}

Adedokun, Omolola A., Ann B. Bessenbacher, Loran C. Parker, Lisa L. Kirkham, and Wilella D. Burgess. 2013. "Research Skills and STEM Undergraduate Research Students' Aspirations for Research Careers: Mediating Effects of Research Self-Efficacy." Journal of Research in Science Teaching 50: 940-951. doi: 10.1002/tea.21102

Auchincloss, Lisa Corwin, Sandra L. Laursen, Janet L. Branchaw, Kevin Eagan, Mark Graham, David I. Hanauer, Gwendolyn Lawrie, et al. 2014. "Assessment of Course-Based Undergraduate Research Experiences: A Meeting Report.” CBE-Life Sciences Education 13(1): 29-40. doi: 10.1187/cbe.14-01-0004
Bauer, Karen W., and Joan S. Bennett. 2003. "Alumni Perceptions Used to Assess Undergraduate Research Experience." Journal of Higher Education 74: 210-230. doi: 10.1080/00221546.2003.11777197

Berkes, Elizabeth. 2007. "Practicing Biology: Undergraduate Laboratory Research, Persistence in Science, and the Impact of Self-Efficacy Beliefs." PhD diss., Washington University in St. Louis.

British Columbia Institute of Technology (BCIT). n.d. "BCIT: Institutional Research Office: Facts and Figures." Accessed February 3, 2020. https://www.bcit.ca/ir/bcit_facts_ and_figures.shtml

Canadian Institutes of Health Research (CIHR), Government of Canada. 2019. "Funding Opportunities Posted between November 29th and December 20th, 2019 by CIHR and Its Partners-CIHR." Accessed December 24, 2019. https://cihr-irsc. gc.ca/e/51805.html

Concordia University. n.d.a "Fast Facts." Accessed February 3, 2020. https://www.concordia.ca/content/concordia/en/about/ fast-facts.html

Concordia University. n.d.b "Meet the Team." Accessed October 19, 2020. https://2019.igem.org/Team:Concordia-Montreal/ Team

Dalhousie University. n.d. "Project Description." Accessed October 19, 2020. http://2017.igem.org/Team:Dalhousie/Description

Eagan, Kevin Jr., Sylvia Hurtado, Mitchell J. Chang, Gina A. Garcia, Felisha A. Herrera, and Juan C. Garibay. 2013. "Making a Difference in Science Education: The Impact of Undergraduate Research Programs." American Educational Research Journal 50: 683-713. doi: 10.3102/0002831213482038

Enrollment Services, McGill University. n.d. "Enrolment Reports." Accessed February 3, 2020. https://www.mcgill.ca/es/ registration-statistics

Estrada, Mica, Paul R. Hernandez, and P. Wesley Schultz. 2018. "A Longitudinal Study of How Quality Mentorship and Research Experience Integrate Underrepresented Minorities into STEM Careers." CBE-Life Sciences Education 17(1): ar9. doi: 10.1187/ cbe.17-04-0066

Hathaway, Russel S., Biren (Ratnesh) A. Nagda, and Sandra R. Gregerman. 2002. "The Relationship of Undergraduate Research Participation to Graduate and Professional Education Pursuit: An Empirical Study." Journal of College Student Development 43: 614-31.

Hernandez, Paul R., Anna Woodcock, Mica Estrada, and P. Wesley Schultz. 2018. "Undergraduate Research Experiences Broaden Diversity in the Scientific Workforce." BioScience 68: 204-211. doi: 10.1093/biosci/bix 163

Institutional Analysis \& Planning, University of Waterloo. 2015. "Student Headcounts." June 2, 2015. https://uwaterloo.ca/institutional-analysis-planning/university-data-and-statistics/studentdata/student-headcounts

McGill University. 2018. "Welcome to iGEM McGill 2018!" http://2018.igem.org/Team:McGill 
Memorial University of Newfoundland. n.d. "Newfoundland and Labrador's University." Accessed February 3, 2020. https:// www.mun.ca/main/

Natural Sciences and Engineering Research Council of Canada (NSERC), Government of Canada. 2016. "NSERC_-Undergraduate Student Research Awards." http://www.nserc-crsng.gc.ca/ students-etudiants/ug-pc/usra-brpc_eng.asp

Russell, Susan H., Mary P. Hancock, and James McCullough. 2007. "Benefits of Undergraduate Research Experiences." Science 316: 548-549.

Sadler, Troy D., Stephen Burgin, Lyle McKinney, and Luis Ponjuan. 2010. "Learning Science through Research Apprenticeships: A Critical Review of the Literature." Journal of Research in Science Teaching 47: 235-256. doi: 10.1002/tea.20326

Science Education Alliance-Phage Hunters Advancing Genomics and Evolutionary Science Program, Howard Hughes Medical Institute. n.d. "SEA-PHAGES." Accessed September 2, 2020. https://seaphages.org/

SFU Science Undergraduate Research Journal (SURJ). n.d. Accessed September 2, 2020. https://sfusurj.com

Shortlidge, Erin E., Gita Bangera, and Sara E. Brownell. 2016. "Faculty Perspectives on Developing and Teaching CourseBased Undergraduate Research Experiences." BioScience 66(1): 54-62. doi: 10.1093/biosci/biv167

Simon Fraser University. n.d. "Fingertip Statistics-Institutional Research and Planning." Accessed February 3, 2020. http:// www.sfu.ca/irp/fingertip-statistics.html

Spell, Rachelle M., Judith A. Guinan, Kristen R. Miller, and Christopher W. Beck. 2014. "Redefining Authentic Research Experiences in Introductory Biology Laboratories and Barriers to Their Implementation." CBE-Life Sciences Education 13(1): 102-110. doi: 10.1187/cbe.13-08-0169

Student Services, University of British Columbia. 2016. "Multidisciplinary Undergraduate Research Conference." December 1, 2016. https://students.ubc.ca/career/events-workshops/multidisciplinary-undergraduate-research-conference

Sun, Evelyn, Julia A. Huggins, Kirstin L. Brown, Rozlyn C. T. Boutin, William D. Ramey, Marcia L. Graves, and David C. Oliver. 2020. "Development of a Peer-Reviewed Open-Access Undergraduate Research Journal." Journal of Microbiology \& Biology Education 21(2): 21.2.62. doi: 10.1128/jmbe.v21i2.2151

Tiny Earth-Studentsourcing Antibiotic Discovery. n.d. "Welcome to Tiny Earth!” Accessed September 2, 2020. https:// tinyearth.wisc.edu/

Undergraduate Journal of Experimental Microbiology and Immunology (UJEMI). n.d. Accessed September 2, 2020. https:// ujemi.microbiology.ubc.ca/

University of Alberta. n.d.a "Facts." Retrieved February 3, 2020, from https://www.ualberta.ca/about/facts.html

University of Alberta. n.d.b "Team UAlberta-2018.igem.org." Accessed October 19, 2020. http://2018.igem.org/Team:Ualberta University of British Columbia. n.d.a "Overview and Facts." Accessed February 3, 2020. https://www.ubc.ca/about/facts.html
University of British Columbia. n.d.b "UBC iGEM." Accessed October 19, 2020. http://www.ubcigem.com/

University of British Columbia. n.d.c "UBC Biomod.” Accessed October 19, 2020. https://ubcbiomod.com

University of Calgary. n.d.a "Our Strategies and Plans.” Accessed February 3, 2020. https://www.calgary.ca/about/our-strategy/ our-strategies-and-plans

University of Calgary. n.d.b "iGEM Calgary." Accessed October 19, 2020. https://igemcalgary.ca

University of Guelph. n.d. "About.” Accessed February 3, 2020. https://www.uoguelph.ca/about

University of Guelph. 2019. "2019 Gold Medal Winners.” Accessed October 19, 2020. https://2019.igem.org/Team:Guelph

University of Ottawa. 2019. "A Story of Underdogs." https://2019. igem.org/Team:uOttawa/Home

University of Ottawa. 2020. "10th Annual Symposium Undergraduate Research Opportunity Program." Accessed April 7, 2020. https://research.uottawa.ca/events/10th-annualsymposium-undergraduate-research-opportunity-program

University of Saskatchewan. n.d.a University of Saskatchewan Undergraduate Research Journal. Accessed September 2, 2020. https://usurj.journals.usask.ca/

University of Saskatchewan. n.d.b "Headcount and Demographics. Statistics. Information and Communications Technology-Reporting and Data Systems." Accessed February 3, 2020. https://www.usask.ca/isa/statistics/students/headcountdemographics.php

University of Toronto. n.d.a "Quick Facts." Accessed February 3, 2020. https://www.utoronto.ca/about-u-of-t/quick-facts

University of Toronto. n.d.b "iGEM Toronto." http://igemtoronto.ca/

University of Toronto. n.d.c "UofT Biomod Team." https:// www.biozone.utoronto.ca/news/uoft-biomod-team

University of Victoria. n.d. "Statistics." Accessed February 3, 2020. https://web.uvic.ca/calendar2019-09/cal/uvic/statistics. html

University of Waterloo. n.d. "Waterloo iGEM: UW's Synthetic Biology Team." Accessed October 20, 2020. http://igem. uwaterloo.ca

Wilfrid Laurier University. n.d. "Laurier Fact Sheet." Accessed February 3, 2020. https://www.wlu.ca/media/assets/resources/ fact-sheet.html

Zydney, Andrew L., Joan S. Bennett, Abdus Shahid, and Karen W. Bauer. 2002. "Impact of Undergraduate Research Experience in Engineering." Journal of Engineering Education 91: 151-157. doi: 10.1002/j.2168-9830.2002.tb00687.x

70 Scholarship and Practice of Undergraduate Research 
David C. Oliver

University of British Columbia, dcoliver@mail.ubc.ca

Evelyn Sun is a postdoctoral teaching fellow in the Department of Microbiology and Immunology at University of British Columbia (UBC) who completed her PhD on the study of bacterial motility and its role in adaptation. She has been teaching science communication for the past two years and currently teaches as well as conducts SoTL research on molecular microbiology CUREs. Her postdoctoral studies include assessing a current CURE model to adapt the model into new CUREs covering various research areas.

Marcia L. Graves is an assistant professor of teaching in the Department of Microbiology and Immunology at UBC who teaches cellular virology and an inquiry-driven lab course in immunology. In her teaching, she focuses on learning outcomes that emphasize building skills in scientific practices such as evidence-based reasoning and scientific writing. She has a special interest in how students engage with and evaluate the primary literature.

David C. Oliver is an associate professor of teaching in the Department of Microbiology and Immunology at UBC who teaches a capstone course-based undergraduate research experience in molecular microbiology. He is particularly interested in leveraging authentic research experience to facilitate team-based and collaborative learning. He is the faculty lead of the Undergraduate Journal of Experimental Microbiology and Immunology, a peer-reviewed, international undergraduate research journal.

\section{Now Available: SPUR Cumulative Index}

(Vols. 1-3, 2017-2020)

Need a tool to find undergraduate research articles? A cumulative index for Scholarship and Practice of Undergraduate Research (SPUR) is now available.

\section{Download at:}

https://www.cur.org/what/publications/ journals/

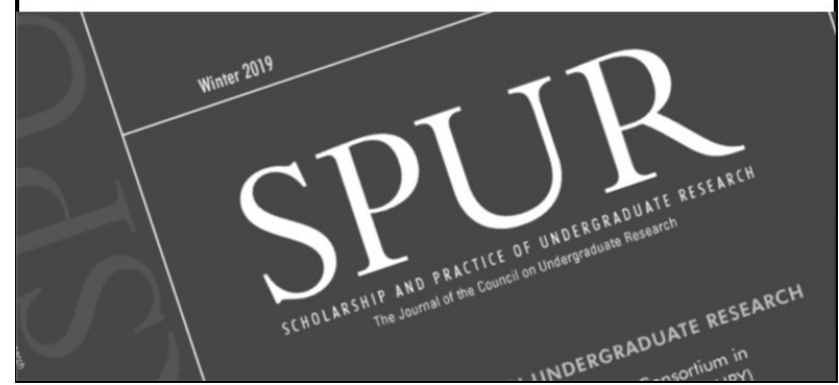

\title{
Did you know?
}

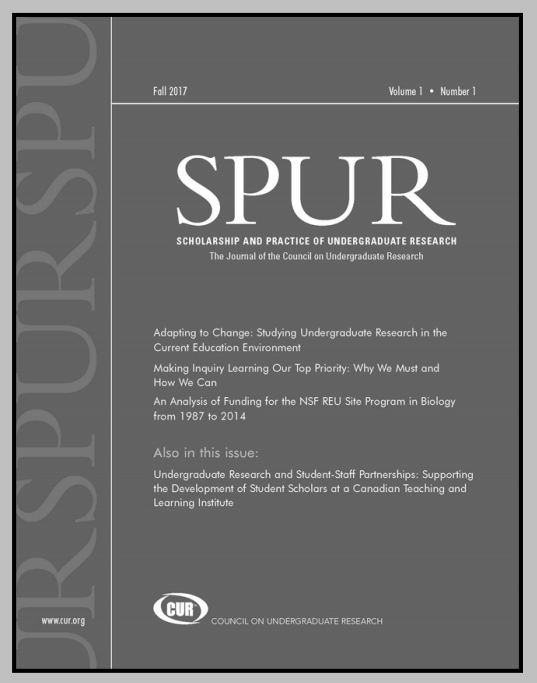

\section{SPUR has an RSS feed for its tables of contents.}

\author{
Subscribe at: \\ https://www.cur.org/ \\ RSS/SPURTOCfeed.xmI
}

